\title{
Formulation and Evaluation of Fish Collagen Extract into Thin Films
}

\author{
Konda Mayuri*, Mazbeen Naznin \\ Department of Pharmaceutics, School of Pharmacy, Nalla Narasimha Reddy Educational \\ Society's Group of Institutions, Hyderabad, India - 500088 \\ *Corresponding Author E-mail: kondamayuri@gmail.com
}

\begin{abstract}
Collagen is a macromolecule of connective tissues in animals and it is cosmopolitan in skin, bones, teeth, tendons, ligament, cartilage, eyes, blood vessels, gut and inter-vertebral discs. Collagen is attracting attention as a biomaterial with several properties such as inducing natural process of blood platelets, cell differentiation, and wound healing, through physical and chemical modifications. The present study was aimed to extract collagen from fish skin and formulate into collagen thin films. Fish collagen thin film was prepared using solvent casting method by using gelatin, sodium alginate, CMC, PEG and ferric oxide, and the formulations were named as $F_{1}$ to $F_{5}$. The prepared thin films were cut into strips of area $2 X 2$ $\mathrm{cm}^{2}$ and evaluated for organoleptic evaluations, film weight, thickness, folding endurance, drug content of films, surface $\mathrm{pH}$, disintegration time, in-vitro dissolution studies, moisture loss and uptake and stability studies. The results of the analysis parameters such as weight, thickness, percentage transparency, swelling property, surface $\mathrm{pH}$ and folding endurance depends on the concentration of sodium alginate and PEG used. Accelerated stability studies have not shown much remarkable changes in the reading of weight, disintegration time and surface $\mathrm{pH}$, thus it indicates that temperature would not alter the properties of the thin film. From the results of percentage drug release collagen is released fast from $F_{3}(60 \%$ in 10 min), and the total drug release was obtained in a span of 40 min, this formulation can be used for the preparation of thin films and $F_{3}$ total drug release was obtained in 60 min.
\end{abstract}

Key Words: Collagen, Gelatin, Sodium alginate, CMC, PEG, Ferric oxide, thin films.

\section{Introduction}

Collagen makes up concerning twenty fifth to thirty fifth of the whole-body macromolecule content in cellular animals. Being major macromolecule of connective tissues in animals, collagen (albuminoid) is cosmopolitan in skin, bones, teeth, tendons, ligament, cartilage, eyes, blood vessels, gut, inter-vertebral discs and most alternative tissues and organs [1].

It's been attracting attention as a biomaterial with several distinctive characteristic like high durability, low antigenicity, bioresorbability, smart biocompatibility, induces natural process of blood platelets, affects cell differentiation, wound healing, and management of varied characteristics through physical and chemical modifications, mould ability, thick and simple for purification. The skin of vertebrates and invertebrates square measure the most supply of collagen used for pharmaceutical, cosmetic and medicine analysis [1]. 
Bovine and porcine skins square measure the most industrial sources for collagen production. Ranging from the 1930s, the primary stuff to be used for the assembly of collagen was porcine skin, and to the present day, the foremost vital stuff for large-scale industrial productions continues to be porcine skin. Porcine skin collagens are rumored to contain bovine spongiform neurological disease (BSE), whereas fish collagen encompasses a lower risk of getting unknown pathogens like animal disease. Besides, religious sentiments for the Jewish and Islamic believers whom proscribe the consumption secular of pork, whereas Hindus forbid the consumption of cow product, have caused pessimism and considerations among customers to use class collagen as a supply. Therefore, plenty of researches are done to seek out an alternate supply of collagen. So far, fish waste collagen was found to own the foremost similar characteristics to class collagen [2].

\section{Thin Film}

Thin-film drug delivery uses a dissolving film or oral drug strip to administer medicine via absorption within the mouth (buccally or sublingually). A film is a ready hydrophilic polymer that quickly dissolves on the tongue or bodily cavity, delivering the drug to the circulation via dissolution once contact with liquid is formed.

Thin-film drug delivery has emerged as a sophisticated ways to the standard tablets, capsules and liquids usually related to prescription and OTC medications. It is similar in size, form and thickness to a stamp, thin-film strips are usually designed for oral administration, with the user putting the strip on or below the tongue (sublingual) or on the within of the cheek (buccal). These drug delivery choices enable the medication to bypass the primary pass metabolism thereby creating the medication additional bioavailable. Because the strip dissolves, the drug will enter the blood stream enterically, buccally or sublingually [3].

\section{MATERIALS AND METHODOLOGY}

\section{Materials}

Collagen was extracted from fish skin, and the other excipients such as gelatin, sodium alginate, Carboxymethyl cellulose, Polyethylene glycol and ferric oxide were obtained from S.D Fine chemicals Ltd. Hyderabad.

\section{Methods}

\section{Extraction of Collagen}

\section{Removal of impurity:}

$100 \mathrm{~g}$ of fish skin was accurately collected after washing and removing the debris.

$>$ Fish skin was cut into small pieces

$>$ The cut pieces were treated with $0.8 \mathrm{~mol} / \mathrm{L} \mathrm{NaCl}$ (1:6 ratios) for $10 \mathrm{~min}$.

$>$ Then washed with cold distilled water $[4,5,6]$. 


\section{Remove non-collagenous matter:}

Skin was treated with $0.1 \mathrm{~mol} / \mathrm{L} \mathrm{NaOH}$ (1:10 ratio) for 3 days by changing $\mathrm{NaOH}$ every day, then it was washed with cold distilled water.

\section{Acid soluble collagen:}

The resultant skin was extracted with 10 volume of $0.5 \mathrm{~mol} / \mathrm{L}$ (1:10 ratio) for 3 days, the process is repeated for 3 more days.

\section{Separation of collagen:}

Acid soluble extract was centrifuged at $6000 \mathrm{rpm}$ for $30 \mathrm{~min}$ at $4^{\circ} \mathrm{C}$.

$>$ Supernatant is salted out using $2 \mathrm{~mol} / \mathrm{L} \mathrm{NaCl}$ for 24 hours at $4^{\circ} \mathrm{C}$.

$>$ Precipitated collagen is centrifuged again at $6000 \mathrm{rpm}$ for $30 \mathrm{~min}$ at $4{ }^{\circ} \mathrm{C}$.

\section{Collagen purification:}

Precipitated collagen is dialysed in $0.02 \mathrm{~mol} / \mathrm{L}$ phosphate buffer solution $\mathrm{pH} 7.2$ for 24 hours at $4^{\circ} \mathrm{C}$.

Residue was placed in dialysis membrane 110 bags for dialysis.

$>$ Finally collagen was collected ${ }^{4,5,6}$.

\section{Qualitative Determination}

\section{SEM Analysis}

Gold coated sample of preserved collagen was placed on the clean SEM plate and was analyzed under scanning electron microscope (WI TECH ALPHA 300 SERIES).

\section{${ }^{1}$ H-NMR analysis}

NMR spectrum was recorded (BRUKER $400 \mathrm{MHz}$ Ultrashield $^{\mathrm{TM}}$ ) in Dimethyl Sulphoxide solvent. The experiment was run at room temperature within which the solvent peak doesn't interfere with any peaks. Once dissolution, approximately $1 \mathrm{ml}$ of the collagen sample solution was transferred to $5 \mathrm{~mm}$ NMR tube. The sample tube was inserted within the magnet and allowed to achieve thermal equilibrium for $10 \mathrm{~min}$ before acting the experiment.

\section{Quantitative Determination}

\section{Determination of $\lambda$ max of collagen in phosphate buffer $\mathrm{pH}-7.2$}

Initially $10 \mathrm{mg}$ of collagen was taken in $10 \mathrm{ml}$ volumetric flask and made up to the volume with phosphate buffer $\mathrm{pH}-7.2(1000 \mu \mathrm{g} / \mathrm{ml})$. From this $1 \mathrm{ml}$ solution was pipette out into 10 $\mathrm{ml}$ volumetric flask and volume was made up with phosphate buffer $\mathrm{pH}-7.2(100 \mu \mathrm{g} / \mathrm{ml})$. This solution was scanned between UV Range 200-400 nm.

\section{Determination of standard curve in buffer using standard:-}

In order to see the standard curve of collagen concentration, collagen customary answer was used (collagen standard obtained from KP Labs, Hyderabad). The collagen standard stock solution was ready dissolving collagen in buffer and distilled water $\left(\mathrm{H}_{2} \mathrm{O}\right)$. Six standard dilutions were ready by dilution of targeted stock $(1000 \mathrm{mg} / \mathrm{ml})$ using the concentration varies of $0.2 \mu \mathrm{g} / \mathrm{ml}$ to $0.6 \mu \mathrm{g} / \mathrm{ml}$. 
The sample extract was ready by dissolving in buffer and diluting by $\mathrm{H}_{2} \mathrm{O}$. The absorbance of the unknown concentration makes up my mind by plotting within the standard curve by using Microsoft excels.

\section{Formulation}

Table 1. Formulation of Thin Film [7]

\begin{tabular}{|l|l|l|l|l|l|l|l|}
\hline $\begin{array}{l}\text { S. } \\
\text { No. }\end{array}$ & Formula & $\begin{array}{c}\text { Drug } \\
(\boldsymbol{\%})\end{array}$ & $\begin{array}{c}\text { Gelatin } \\
(\boldsymbol{\%})\end{array}$ & $\begin{array}{c}\text { Sodium } \\
\text { alginate } \\
(\boldsymbol{\%})\end{array}$ & $\begin{array}{c}\text { Carboxymethyl } \\
\text { cellulose } \\
(\boldsymbol{\%})\end{array}$ & $\begin{array}{c}\text { Polyethylene } \\
\text { glycol } \\
(\boldsymbol{\%})\end{array}$ & $\begin{array}{c}\text { Ferric } \\
\text { oxide } \\
(\boldsymbol{\%})\end{array}$ \\
\hline $\mathbf{1}$ & F1 & 0.6 & 3.33 & 0.6 & 0.6 & 0.6 & - \\
\hline $\mathbf{2}$ & F2 & 1 & 2.5 & 1 & 0.5 & 1 & - \\
\hline $\mathbf{3}$ & F3 & 1.2 & 4 & 1.2 & 0.4 & 1.2 & - \\
\hline $\mathbf{4}$ & F4 & 1.33 & 5 & 1.33 & 0.33 & 1.33 & - \\
\hline $\mathbf{5}$ & F5 & 1.42 & 5.71 & 1.42 & 0.2 & 1.42 & - \\
\hline
\end{tabular}

\section{Method of Film Preparation}

Solvent casting technique is employed to arrange collagen thin films.

Step 1: The optimized collagen extract is dissolved in $2 \mathrm{ml}$ buffer; to the current buffer extract gelatine $(3.33 \%)$, sodium alginate $(0.6 \%)$, carboxymethyle cellulose $(0.6 \%)$, polyethylene glycol $(0.6 \%)$, and ferric oxide were supplementary so created up the amount as per the Petri plate calculation demand.

Step 2: Weighed polymer was placed within the beaker as per the compositions, and also the higher than formulation mixture was poured in to the beaker sideways specified the polymer powder is totally immersed.

Step 3: Place the beaker containing the formulation mixture within the hot plate to stop the formation of bubbles. Place the formulation once the polymer is totally dissolved.

Step 4: The resultant solution is poured within the Petri plate and dried long at temperature $\left(25^{\circ} \mathrm{C}-35^{\circ} \mathrm{C}\right)$.

Step 5: The dried film are into squares on a $2 \times 2 \mathrm{of}^{2}$ films and hold on within the tin foil for additional analysis [8].

The same procedure is followed by all the formulations.

\section{Petri plate calculation:-}

Calculation of drug loaded within the film:

1. Diameter of Petri dish bottom $=14 \mathrm{~cm}$

Radius of the Petri dish bottom $=$ Diameter $/ 2=7 \mathrm{~cm}$.

Radius of bottom Petri plate $=\pi \mathrm{r} 2=3.14 \times 7 \times 7=153.86 \mathrm{~cm}^{2}$

Now, Dose is $2 \mathrm{mg}$ and cut the pieces in $2 \mathrm{~cm} \mathrm{X} 2 \mathrm{~cm}=4 \mathrm{~cm}^{2}$

$4 \mathrm{~cm}^{2}$ contain $2 \mathrm{mg}$ drug so, $153.86 \mathrm{~cm}^{2}$ contain (?) Drug $=\mathbf{7 7} \mathbf{m g}$ of drug.

2. Diameter of Petri dish top $=14.5 \mathrm{~cm}$

Radius of the Petri dish bottom $=$ Diameter $2=7.25 \mathrm{~cm}$.

Radius of bottom Petri plate $=\pi \mathrm{r} 2=3.14 \times 7.25 \times 7.25=165 \mathrm{~cm}^{2}$

Now, Dose is $2 \mathrm{mg}$ and cut the pieces in $2 \mathrm{~cm} \mathrm{X} 2 \mathrm{~cm}=4 \mathrm{~cm}^{2}$

$4 \mathrm{~cm}^{2}$ contain $2 \mathrm{mg}$ drug so, $165 \mathrm{~cm}^{2}$ contain (?) Drug $=\mathbf{8 2 . 5 m g}$ of drug. 


\section{EVALUATION}

\section{Fourier Transforms Infrared (FTIR) Spectroscopy}

The drug-polymer compatibility was confirmed by closing FTIR studies. Drug, compound and physical mixture of drug-polymer were subjected to FTIR analysis victimization FTIR 8400 S Shimadzu, Japan. Samples were ready in buffer ( $2 \mathrm{mg}$ sample in 200 $\mathrm{mg}$ buffer) with a scan vary of $450-4000 \mathrm{~cm}^{-1}$ and therefore the resolution of $4 \mathrm{~cm}^{-1}$. FTIR studies were administrated for collagen pure drug, physical mixture of optimized formulation and optimized formulation.

\section{Method of Evaluation}

\section{Organoleptic Evaluations}

Formulated films were evaluated for organoleptic evaluations like Colour, odour and taste.

\section{Thickness of Thin Film}

Thickness of a film is decided by exploitation digital screw gauge micrometer and so afterwards mean average is calculated. Generally, 3 readings from all the batches are determined and average is calculated.

\section{Weight Uniformity}

The cast film was cut at completely different places and therefore the weight of every film was checked with the help of an electronic balance and therefore the average weight was calculated.

\section{Folding Endurance}

Folding endurance is another procedure to estimate the mechanical properties of a movie. It's measured by repeatedly folding a film at a same point until it breaks. Folding endurance value is range of times the film is folded-up while not breaking. Higher folding endurance worth depicts the additional mechanical strength of a film. An immediate relation exists between mechanical strength and folding endurance of films.

The cast film was cut at completely different places and therefore the weight of every film was checked with the assistance of electronic balance and therefore the average weight was calculated [9].

\section{Percentage Elongation}

Upon exerting stress on a film, the specimen stretches that is referred as strain. Strain is outlined as amendment long of film divided by its original/initial length of the film specimen. Percentage elongation is said quantitatively to the number of plasticizer utilized in film formulation. Increased plasticizer concentration within the film usually ends up in increased elongation of the strip. It's determined by the subsequent formula:

Percentage elongation $=\frac{\text { change in length }}{\text { initial length }} \times 100$ 


\section{Disintegration Time}

It is performed by Petri dish method. Petri dish method: $10 \mathrm{ml}$ of distilled water was placed in a Petri dish and one film was added on the surface of the water and therefore the time measured till the thin film was dissolved fully and average values were reported.

\section{Surface pH}

The surface $\mathrm{pH}$ of the films was resolute so as to research the chance of any aspect effects in vivo. As associate degree acidic or alkaline $\mathrm{pH}$ might cause irritation to the wound, it had been determined to stay the surface $\mathrm{pH}$ as on the brink of neutral as potential. A glass electrode has been used for this test. A $2 \mathrm{X} 2 \mathrm{~cm}$ film was dissolved in $2 \mathrm{ml}$ of water. The $\mathrm{pH}$ was measured by transferral the conductor to bear with the surface of the film and permitting it to equilibrate for 1minute. These tests were conducted in triplicate and average readings were documented.

\section{Drug Content of Films (\% Assay)}

Dissolve thin films in $100 \mathrm{ml}$ of phosphate buff $\mathrm{pH} \mathrm{7.2,} \mathrm{Absorbance} \mathrm{of} \mathrm{standard} \mathrm{preparation}$ and test preparation was taken using ultraviolet light double beam spectrophotometer at 226 $\mathrm{nm}[10]$.

\section{Transparency}

Transparency of a strip is set by employing a UV-spectrophotometer. This test is performed for visual look of the formulation. Film specimen is remove rectangular shapes and placed on the inside aspect of the photometer cell. Transmittance of the film is puzzled out at $400 \mathrm{~nm}$ wavelength.

\section{Swelling property}

Simulated saliva solution is employed to ascertain the swelling studies of films. Initial weight of film is set and is placed in pre-weighed glass slide. This slide containing film is then unfit into simulated saliva solution. Increase within the weight of film is noted at constant predetermined time intervals till no additional increase in weight. Degree of swelling is set by these parameters:

Degree of swelling $=\frac{\text { final weight }(W t)-\text { initial weight }(W o)}{\text { initial weight }(W o)}$

\section{Where,}

$\mathrm{Wt}=$ weight of film at time interval $\mathrm{t}$;

$\mathrm{W}_{0}=$ weight of film at time 0 .

\section{Tensile Strength}

Tensile strength is that the capability of a material/structure to resist load tending to elongate, resist tension (being force apart), measured by the most stress that a material will withstand up to whereas being stretched or force before breaking. It's determined by the subsequent formula: 


$$
\begin{aligned}
\text { Stress } & =\frac{\text { Force }}{\text { Area }} \\
\text { Strain } & =\frac{\text { Length of } \text { stretch }}{\text { Original length }}
\end{aligned}
$$

\section{Moisture uptake}

Moisture uptake of a film is set by initial cutting the film with the dimension of $2 \mathrm{X} 2 \mathrm{~cm} 2$. After these films are exposed to setting with a ratio of $75 \%$ at temperature for 5 days. Wet uptake is set as \% weight gain of the films [11].

$$
\text { Percentage moisture uptake }=\frac{\text { Final weight }- \text { Initial weight }}{\text { Initial weight }} \times 100
$$

\section{Moisture Loss}

Percent moisture loss could be a parameter that determines the hygroscopicity of a film. Usually, this parameter is set by initial finding the initial weight of the film, afterward; put this film in refrigerator for 5 days. Refrigerator contains calcium carbonate. Once 5 days, films are taken out and weighed once more. Wet loss is set by applying the subsequent formula:

Percentage moisture loss $=\frac{\text { Initial weight }- \text { Final weight }}{\text { Initial weight }} X 100$

\section{Diffusion of Thin Film}

In-vitro diffusion Studies: Phosphate buffer of $\mathrm{pH} 7.2$ was taken as dissolution fluid in receptor medium for In-vitro diffusion study. The prehydrated cell phone membrane was utilized in changed franz diffusion cell as a membrane barrier. The test sample was taken in donor cell then cellophane membrane was mounted in between donor and receptor compartment of diffusion cell. The receptor compartment was full of phosphate buffer $(30 \mathrm{ml})$ of 7.2. The temperature of diffusion medium was thermostatically controlled at $37^{0} \pm 0.5^{0} \mathrm{C}$ by encompassing water in jacket and also the medium was stirred by magnetic stirrer at 50 $\mathrm{rpm}$. The samples were collected at predetermined time intervals and again replaced by same quantity of new fluid. The samples withdrawn were spectrophotometrically calculated [11].

\section{Stability studies}

Accelerated stability studies were conducted by inserting the sample at $4{ }^{\circ} \mathrm{C}$ and $40^{\circ} \mathrm{C}$ for 5 days and therefore the following parameters are tested daily.

- Weight.

- Surface $\mathrm{pH}$.

- Disintegration time.

\section{RESULTS AND DISCUSSION}

\section{Collagen}

\section{Extraction of Collagen}

Collagen was extracted from fish skin in accordance with the prescribed procedure. Fish skin chopped separately into small pieces and treated with $0.8 \mathrm{~mol} / \mathrm{L}$ sodium chloride $(\mathrm{NaCl})$ at a 
ratio of 1:6 (w/v) for $10 \mathrm{~min}$, to remove the impurities. This procedure was repeatedly done for 3 times and later washed with chilled distilled water. Then they were reacted with 0.1 $\mathrm{mol} / \mathrm{L}$ sodium hydroxide $(\mathrm{NaOH})$ at a proportion of 1:10 (w/v) for 3 consecutive days to take away the non-collagenous proteins. The ammonium hydroxide was replaced each day and finally treated with cold distilled water. Collagen was then extracted using acetic acid. Acid soluble collagen (ASC) was extracted twice using 10 volumes of $0.5 \mathrm{~mol} / \mathrm{L}$ of the acetic acid for 3 days. Following every extraction, the prepared solution was centrifuged at 9,000 rpm for 20 minutes at $4{ }^{\circ} \mathrm{C}$. The supernatant liquid was salted out with $2 \mathrm{~mol} / \mathrm{L} \mathrm{NaCl}$ for $24 \mathrm{~h}$ at 4 ${ }^{\circ} \mathrm{C}$. The precipitated collagen was centrifuged again at $9,000 \mathrm{~g}$ for $20 \mathrm{~min}$ at $4{ }^{\circ} \mathrm{C}$. The residue was placed in the dialysis membrane- 110 bags and dialyzed against $0.02 \mathrm{~mol} / \mathrm{L}$ phosphate buffer ( $\mathrm{pH}$ 7.2) for $24 \mathrm{~h}$ at $4{ }^{\circ} \mathrm{C}$. The yield of collagen was calculated based on the hydroxyproline content in extracted collagen.
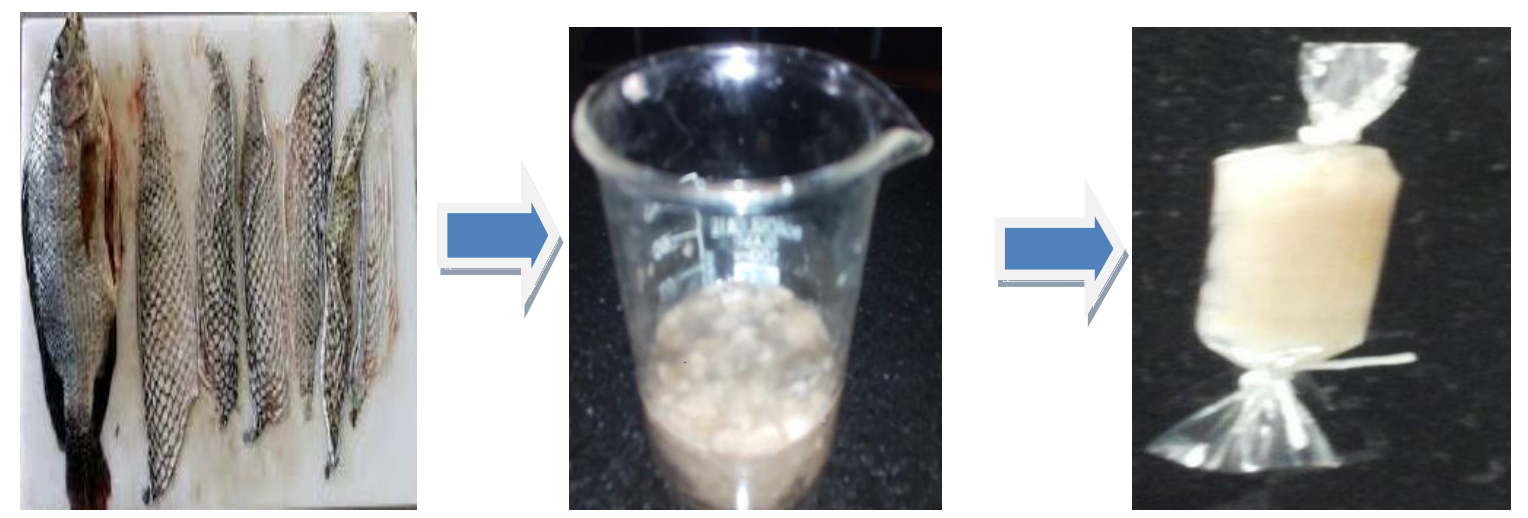

Figure 1. Extract of Collagen

\section{Identification of Collagen Extract}

Table 2. Identification tests of Collagen Extract

\begin{tabular}{|l|l|l|}
\hline \multicolumn{1}{|c|}{ Identification test } & \multicolumn{1}{|c|}{ Observation } & \multicolumn{1}{c|}{ Collagen extract } \\
\hline Biuret test & Not violet precipitate & Positive \\
\hline Millons test & Violet precipitate & Positive \\
\hline Ninhydrin test & Violet precipitate & Positive \\
\hline
\end{tabular}

Identification tests are conducted to confirm the presence of peptide bonds and the tests results are positive. (Table 2)

\section{Qualitative Determination}

\section{SEM analysis}

The samples was observed under scanning electron microscope (WI TECH ALPHA 300 SERIES) and shown as figure 2. 


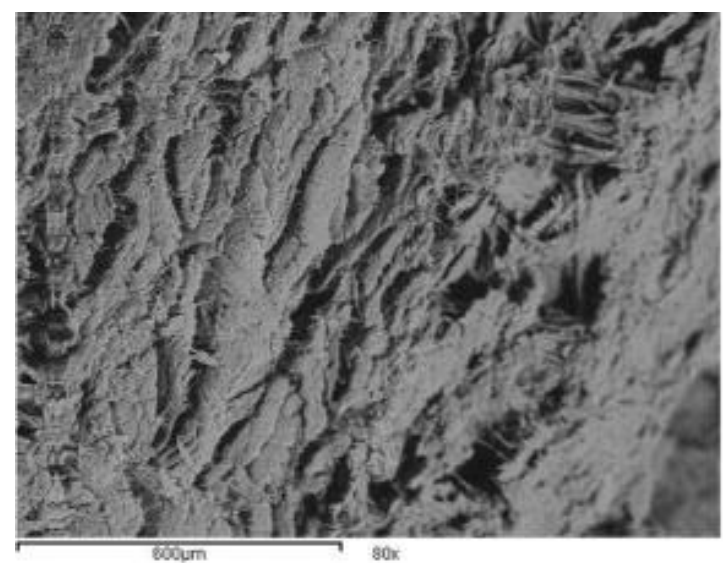

Figure 2. SEM of Collagen

\section{${ }^{1}$ H-NMR}

${ }^{1} \mathrm{H}-\mathrm{NMR}$ spectral analysis may be powerful technique to supply information concerning the hydrogen atom position. Figure 3 shows the ${ }^{1} \mathrm{H}$ NMR spectrum of acid soluble collagen that shows a main strong band between 4.5-5.0 ppm indicating the occurrence of hydration water. It also represents a key singlet band positioned at $1.5 \mathrm{ppm}$ and some additional bands at 2.5 , 3.0 and $3.3 \mathrm{ppm}$ indicating the unfolding nature of protein and utilization of amide groups and $\alpha$-carbon protons in the protein structure.

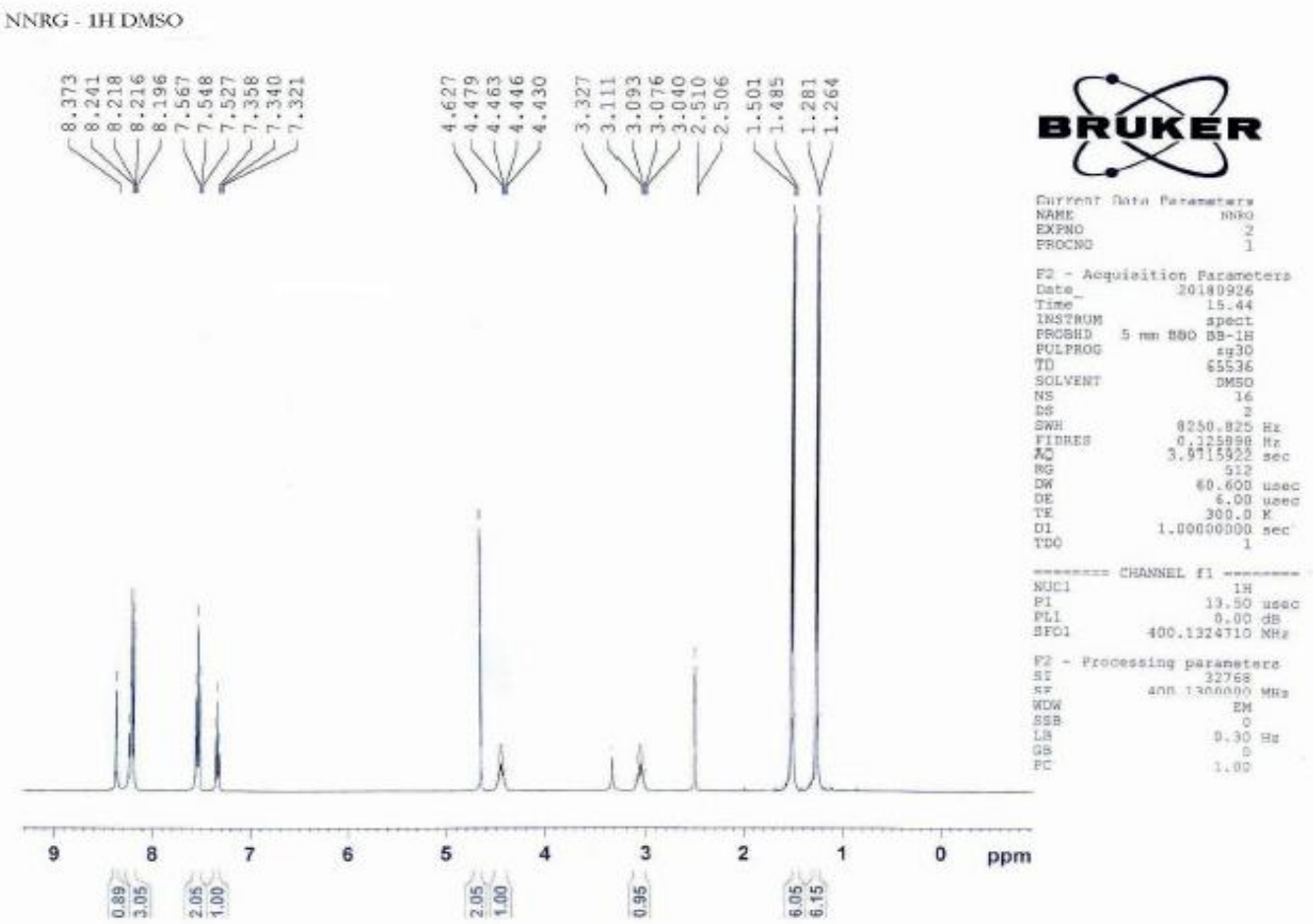

Figure 3: ${ }^{1} \mathrm{H}-\mathrm{NMR}$ spectra of Collagen 


\section{Quantitative Determination of Collagen Content}

\section{Determination of $\lambda$ max of collagen in phosphate buffer pH-7.2}

Determination of $\lambda$ max of collagen was done in $\mathrm{pH}-7.2$ buffer medium and was found to be $226 \mathrm{~nm}$.

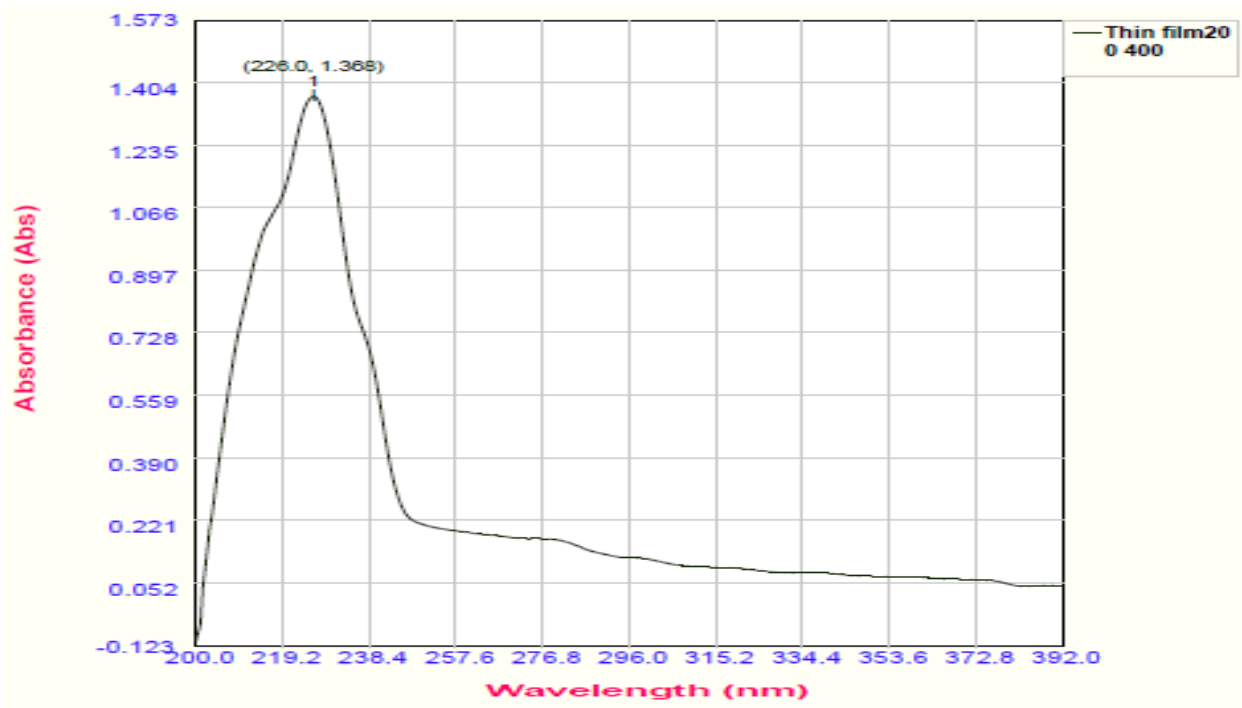

Figure 4: $\lambda$ max of Collagen

Standard curve of collagen extract for quantitative determination

Table 3: Standard absorbance values of Collagen dilutions

\begin{tabular}{|c|c|c|}
\hline S.No. & Concentration $(\boldsymbol{\mu g} / \mathbf{m l})$ & Absorbance \\
\hline $\mathbf{1}$ & 0 & 0 \\
\hline $\mathbf{2}$ & 10 & 0.0609 \\
\hline $\mathbf{3}$ & 20 & 0.0812 \\
\hline $\mathbf{4}$ & 30 & 0.0992 \\
\hline $\mathbf{5}$ & 40 & 0.1345 \\
\hline $\mathbf{6}$ & 50 & 0.1622 \\
\hline $\mathbf{7}$ & 60 & 0.1872 \\
\hline $\mathbf{8}$ & 70 & 0.2194 \\
\hline $\mathbf{9}$ & 80 & 0.2319 \\
\hline $\mathbf{1 0}$ & 90 & 0.2569 \\
\hline $\mathbf{1 1}$ & 100 & 0.3731 \\
\hline
\end{tabular}

The standard of collagen is dissolved in buffer and diluted as mentioned within the table 3 . The absorbance was taken by using UV-Vis photometer at $226 \mathrm{~nm}$. 


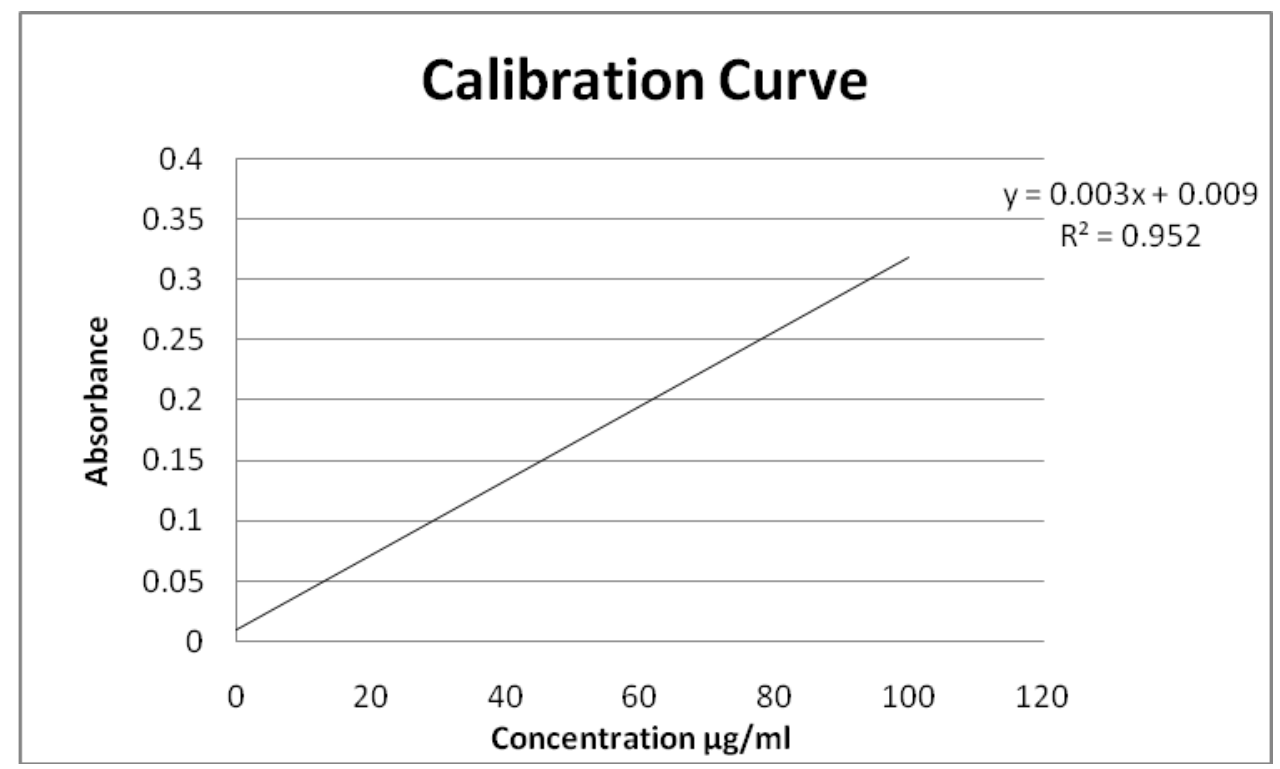

Figure 5: Calibration curve of Collagen

\section{Evaluation of Thin Films}

\section{Fourier Transforms Infrared (FTIR) Spectroscopy}

The FTIR studies were done to evaluate any potential interaction between collagen and formulated excipients. The recorded IR spectra did not demonstrate any modification in IR peaks, signifying no potential interaction between excipients and collagen.

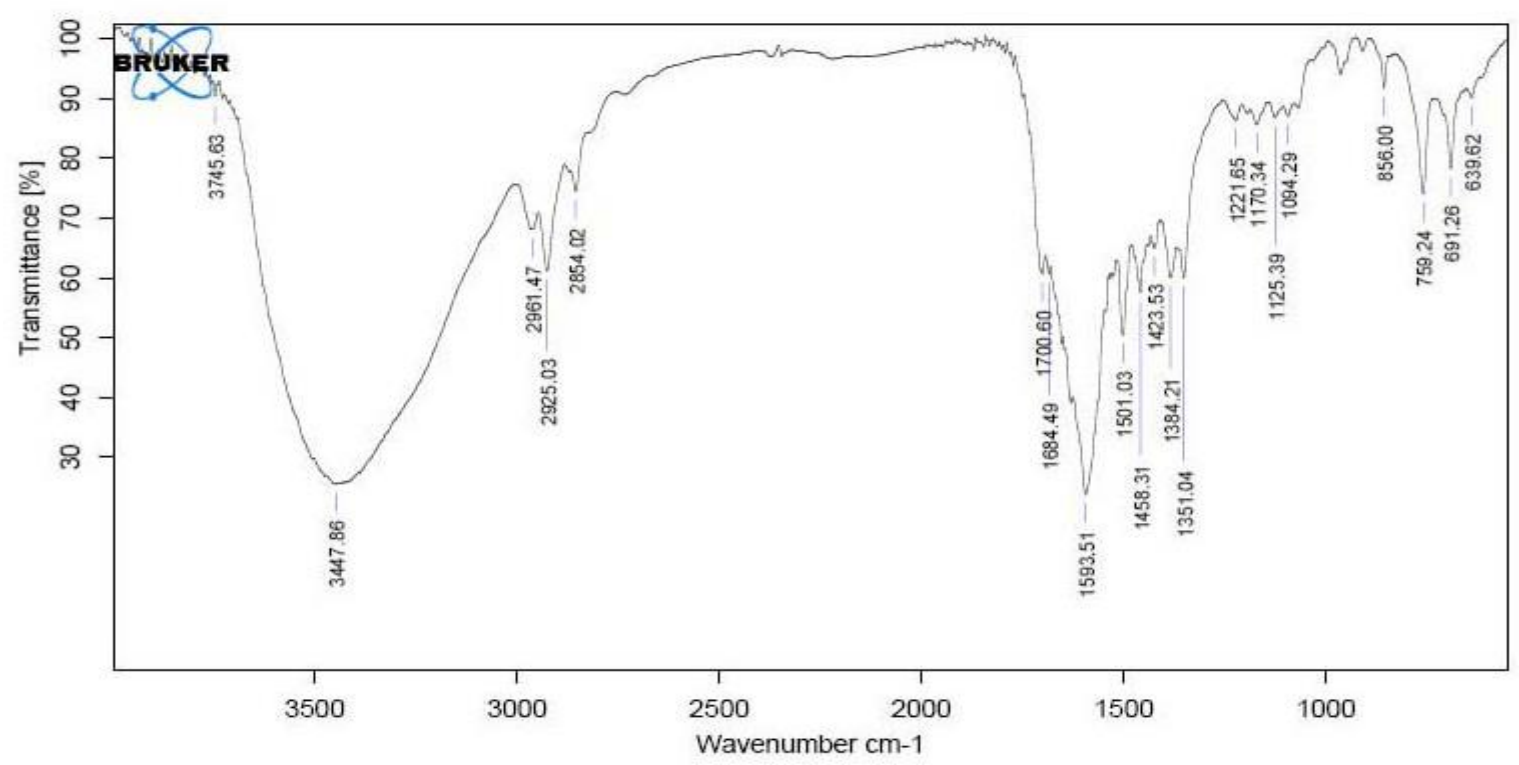

Figure 6: FTIR spectrum of Collagen 


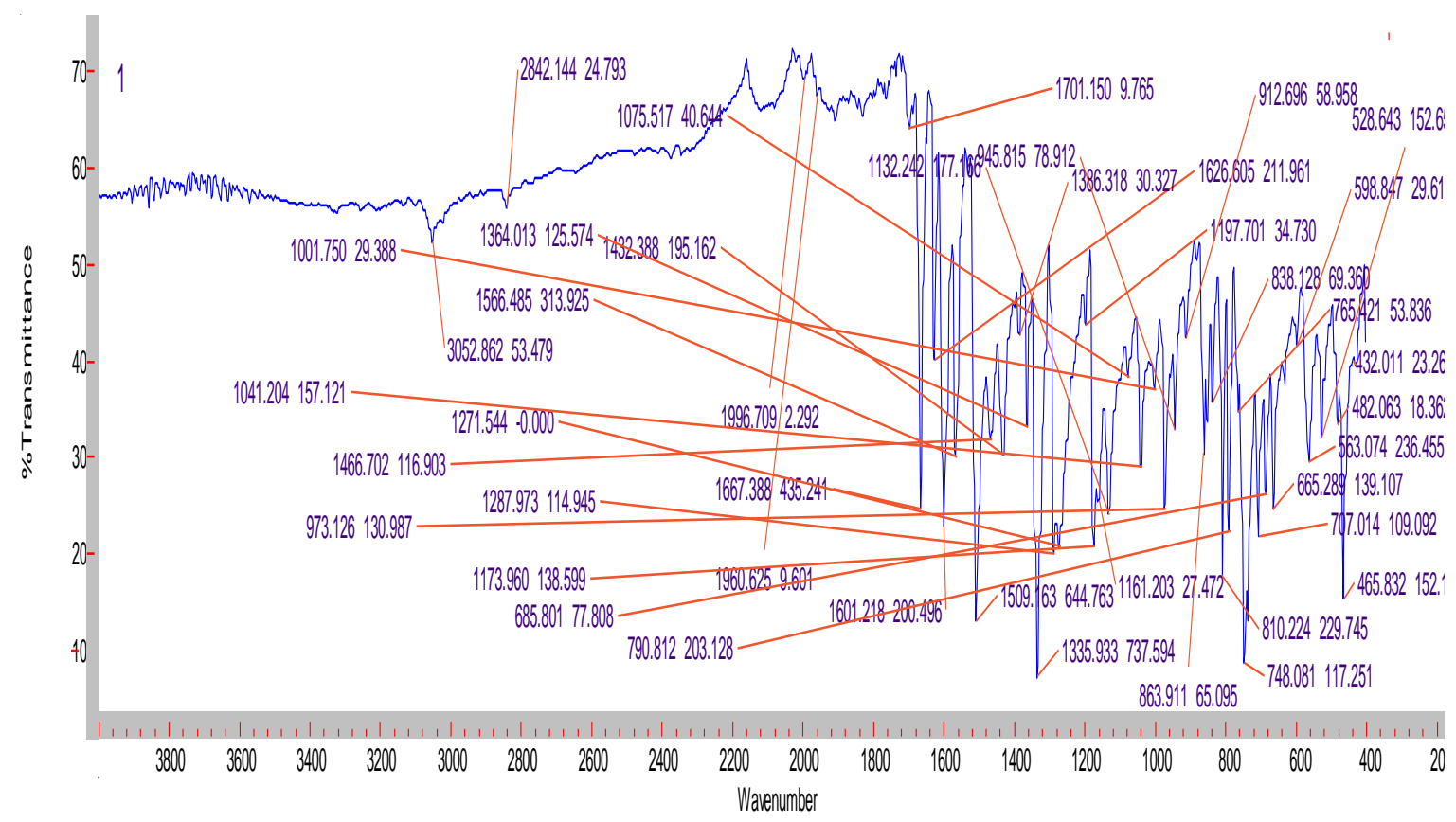

Figure 7: FTIR spectrum of collagen and excipients

\section{Physical Appearance}

Physical appearance was examined with visual examination of films and texture by touching it. The ready films squares were having visually smooth surface and therefore the drug/polymer distribution was uniform.

\section{Thickness of Thin Film}

Thickness of every film was measured using digital Screw gauge at different locations. The thickness of the thin films varied between 0.04 to $0.011 \mathrm{~mm}$. According to the obtained results it absolutely was discovered that increase in polymer concentration will increases thickness of the film. It is vital issue to contemplate that ascertains the accuracy and uniform distribution of dose within the strip.

\section{Weight Variation Test}

The weight of every film was found to be uniform. It had been found to be in a range of 0.49 to $9.40 \mathrm{mg}$. In step with the obtained results it had been ascertained that increase in compound concentration will increase weight of the film. Weight variation is a crucial parameter to consider as any variation within the weight of film ends up in under medication or over medication.

\section{Surface pH}

The surface $\mathrm{pH}$ scale of all the films exhibited uniformity in their values and were found to be ranges 6.83 to 7.40 indicating its compatibility with wound $\mathrm{pH}$ scale. Thus no skin irritation was expected and ultimately achieved patient compliance. 


\section{Folding Endurance}

The folding endurance offers an inspiration over the pliability of films as brittle films offers less value of folding endurance and films with good flexibility offers high value of folding endurance. The film that shows folding endurance between 109 to 120 times represents good mechanical characteristics. Also, it had been ascertained that increase in thickness of polymer concentration decreases folding endurance value. The folding endurance was found to be highest for formulation.

\section{Drug Content Estimation}

Thin films square measure dissolved in $100 \mathrm{ml}$ of phosphate buffer $\mathrm{pH} 7.2$, Absorbance of normal preparation and test preparation was taken using ultraviolet (UV) double beam photometer at $226 \mathrm{~nm}$.

\section{Percentage Moisture Absorption}

Percentage moisture absorption (PMA) test was conducted on thin films of collagen to see its physical stability of the film at high humid conditions. Optimum moisture content in the formulations helps the film to remain stable, non brittle and free from complete drying. PMA of F3 was found to be $20.68 \%$ as highest and F5 was with the lowest value $3.9 \%$.

\section{Percentage Moisture Loss}

Percentage moisture loss (PML) was conducted on thin films of collagen to see the integrity of the film at dry conditions. PML of $\mathrm{F} 1$ at room temperature $\left(<25^{\circ} \mathrm{C}\right)$ was found to be $2.83 \%$ and $5.24 \%$ when kept in hot air oven $\left(<50^{\circ} \mathrm{C}\right)$, which indicted the suitable observations.

\section{Percent Elongation}

Percent elongation was conducted on thin films of collagen to see the elongation capability of the film. The obtained values were in a same range of $110-125 \%$. These results were obtained constant due to the constant concentration of plasticizer (PEG) used which is $10 \%$.

\section{Swelling Index}

Swelling index was conducted on thin films of collagen to see the quantity of increased weight of the film. The ascertained results were within the table. The obtained values were in a same range of 1.83 to 329.7 . Increased polymer concentrations have increased the swelling index and this criterion has been proved in all the formulation form F1 to F5.

\section{Transparency}

Transparency was conducted on thin films of collagen under UV at $226 \mathrm{~nm}$ to see the percentage transparency of the film. The obtained values were in a same range of 0.0323 to 0.2119 .

\section{Disintegration Test}

The time it took for the film to visually break apart in water was recorded as the disintegration time. The mean disintegration time was 5:20 to 8:40 minute. Supported previous experience, we defined a disintegration time of less than 9 minutes to be considered 
acceptable for this formulation. The disintegration time can be simply adjusted by standardization the composition of the film.

\section{In-Vitro Diffusion Studies for Thin Film}

The release profiles of the thin film are shown in Table 4 . In this formulation, $80 \%$ drug release was achieved in $15 \pm 20$ minutes, and total drug release was achieved within time interval. When all the formulations were compared F3 indicated fat release pattern, it released collagen $85.54 \%$ in 15 minutes and the complete release was contained in 30 minutes itself.

Table 4. In-Vitro diffusion drug release of thin film in phosphate buffer $\mathbf{p H} 7.2$

\begin{tabular}{|c|c|c|c|c|l|l|l|l|}
\hline \multirow{2}{*}{ Formulation } & \multicolumn{7}{|c|}{ \% Drug Release } \\
\cline { 2 - 9 } & $\mathbf{5 m i n}$ & $\mathbf{1 0 m i n}$ & $\mathbf{1 5} \mathbf{m i n}$ & $\mathbf{2 0 m i n}$ & $\mathbf{3 0}$ min & $\mathbf{4 0}$ min & $\mathbf{6 0 m i n}$ & $\mathbf{1 2 0}$ min \\
\hline $\mathrm{F}_{1}$ & 38.00 & 66.16 & 76.61 & 81.22 & 84.28 & 96.76 & 99.99 & 99.99 \\
\hline $\mathrm{F}_{2}$ & 39.10 & 49.09 & 74.09 & 80.69 & 82.33 & 91.80 & 96.03 & 99.99 \\
\hline $\mathrm{F}_{3}$ & 59.41 & 68.91 & 85.54 & 96.23 & 99.99 & 99.99 & 99.99 & 99.99 \\
\hline $\mathrm{F}_{4}$ & 39.80 & 51.08 & 65.76 & 76.76 & 85.45 & 92.22 & 95.82 & 99.99 \\
\hline $\mathrm{F}_{5}$ & 51.10 & 67.98 & 74.38 & 78.35 & 84.78 & 98.02 & 99.21 & 99.99 \\
\hline
\end{tabular}

\section{Stability Studies}

Accelerated stability studies were conducted by putting the sample at $4{ }^{\circ} \mathrm{C}$ and $50^{\circ} \mathrm{C}$ for 5 days and therefore the weight, surface $\mathrm{pH}$ and disintegration parameters are noted on day 1 and day 5 . The obtained results are mentioned in the table 5.

The results illustrate that weight, surface $\mathrm{pH}$ and disintegration time for the formulations at day 1 and day 5 of various storage condition failed to show lot of variation, which indicate that accelerated temperature conditions do not alter the properties of the formulations.

Table 5. Stability studies of thin films of collagen

\begin{tabular}{|c|c|c|c|c|c|c|c|}
\hline \multirow{2}{*}{\multicolumn{2}{|c|}{ Stability }} & \multirow{3}{*}{$\begin{array}{l}\text { Days } \\
\text { Day } 1\end{array}$} & \multicolumn{5}{|c|}{ Formulation } \\
\hline & & & F1 & F2 & F3 & F4 & F5 \\
\hline \multirow{6}{*}{$50^{0} \mathrm{C}$} & \multirow[t]{2}{*}{ Weight } & & 24.7 & 20.3 & 20.4 & 33.2 & 26.9 \\
\hline & & Day 5 & 24.0 & 19.5 & 17.2 & 32.5 & 25.8 \\
\hline & \multirow[t]{2}{*}{ pH } & Day 1 & 7.24 & 6.89 & 7.16 & 7.25 & 6.87 \\
\hline & & Day 5 & 7.18 & 6.70 & 7.10 & 7.19 & 6.79 \\
\hline & \multirow{2}{*}{$\begin{array}{l}\text { Disintegration } \\
\text { time }\end{array}$} & Day 1 & 8.00 & 7.60 & 7.04 & 7.37 & 8.19 \\
\hline & & Day 5 & 8.30 & 8.00 & 7.50 & 7.80 & 8.44 \\
\hline \multirow{6}{*}{$4^{0} \mathrm{C}$} & \multirow[t]{2}{*}{ Weight } & Day 1 & 22.4 & 18.3 & 20.3 & 29.9 & 27.2 \\
\hline & & Day 5 & 25.2 & 19.3 & 22.5 & 31.2 & 28.3 \\
\hline & \multirow[t]{2}{*}{ pH } & Day 1 & 7.03 & 6.67 & 7.14 & 6.81 & 7.15 \\
\hline & & Day 5 & 7.01 & 6.72 & 7.18 & 6.88 & 7.22 \\
\hline & \multirow{2}{*}{$\begin{array}{l}\text { Disintegration } \\
\text { time }\end{array}$} & Day 1 & 7.40 & 8.10 & 8.06 & 8.08 & 8.15 \\
\hline & & Day 5 & 8.10 & 8.40 & 8.20 & 8.30 & 8.30 \\
\hline
\end{tabular}




\section{CONCLUSION}

Thin films prepared within the study exhibited smart film characteristic options as indicated by thickness measured, folding endurance, disintegration time, drug content, wet uptake and loss, share elongation etc. The prepared films were found to be uniform, flexible, stabilised at high and low temperatures. Collagen thin films are meant for the appliance within the wound healing and those them are associate degree innovative and promising indefinite quantity type particularly for the utilization in medical specialty and gerontology. In gift analysis work, a trial has been created to organize mouth dissolving films of scleroprotein by solvent casting methodology by victimization drug, Gelatine, sodium Alginate, CMC, PEG etc. collagen has been extracted from fish skin and identification, qualitative and quantitative determination of phytotoxin extract was conducted by $1 \mathrm{H}-\mathrm{NMR}$, SEM, Chemical identification take a look at and UV-Vis spectrophotometry. The thin films were evaluated for prescribed formulation parameters and Pre formulation study involving FTIR study showed no interaction between drug and chemical compound. Disintegration time was noted to be $9 \mathrm{~min}$ on an average and surface $\mathrm{pH}$ makes it suitable for drug delivery. Percentage of Transparency was in the range of 0.0323 to 0.2119 , which was due to the light skin colour of the collagen extract. Later stability studies of this formulation were indicating that there was no degradation of the formulation at high temperature and humidity conditions which makes it suitable for varied storage conditions and it was indicating that this formulation was stable.

\section{ACKNOWLEDGMENT}

The authors are thankful to KP Labs, Hyderabad, India, and SD Fines Chemicals, Hyderabad for providing gift samples. Authors are also thankful to management of Nalla Narasimha Reddy Group of Institutions, Chowdariguda, Ghatkesar.

\section{CONFLICT OF INTEREST}

There are no conflicts of interest to be declared.

\section{BIBLIOGRAPHY}

1. Oliveira, S, R Ringshia, $R$ Legeros, E Clark, L Terracio, C Teixeira M Yost, An improved collagen scaffold for skeletal regeneration, Journal of Biomedical Material. Vol. 94, no.2, (2009), pp. 371-379.

2. Gould, L. J, Topical collagen-based biomaterials for chronic wounds: rationale and clinical application, Advances in Wound Care. Vol 5, no. 2, (2016), pp.19-31.

3. Pandya K, Patel KR, Patel MR and Patel NM, Fast dissolving films: A novel approach to oral drug delivery, Int J Pharm Teaching \& Practices. Vol 4, no.2, (2013), pp. 655-651.

4. G.S. Hema, A simple method for isolation of fish skin collagen-biochemical characterization of skin collgagen extracted from Albacore Tuna (Thunnus Alalunga), Dog Shark (Scoliodon Sorrakowah), and Rohu (Labeo Rohita), Annals of Biological Research. Vol 4, no. 1, (2013), pp.271-278. 
5. Nagarajan Muralidharan, Skin, bone and muscle collagen extraction from the trash fish, leather jacket (Odonus niger) and their characterization, J Food Sci Technol. Vol 50, no. 6, (2013), pp. 1106-1113.

6. Jayalakshmi Krishnamoorthia, Isolation and partial characterization of collagen from outer skin of Sepiapharaonis (Ehrenberg, 1831) from Puducherry coas, Biochemistry and Biophysics Reports. Vol 1, (2017), pp. 39-45.

7. Prajapati V, Bansal $M$ and Sharma PK, Mucoa dhesive buccal patches and use of natural polymer in its preparation- A review, Int J PharmTech Res. Vol 4, no. 2, (2012), pp.582-589.

8. HD Karen, DM Patel, AR Jasakiya, and CN Patel, Development of Oral Strip for Loratidine and Invitro Evaluation, Int. J. Pharma. Pharmacology. Vol 2, no. 8, (2013), pp.125-30.

9. Mc-Elnay JC, Al-Furaih TA, Hughes CM, Scott MG, Elborn JS, Nicholls DP, The effect of pH on the buccal and sublingual absorption of captopril, Eur J Clin Pharmacol. Vol 48, no. 5, (1995), pp. 373-379.

10. RP Narayana, KM Sravan, M Reddy, K Ravishanker, Formulation and Evaluation of Fast Dissolving Films of Loratidine by Solvent Casting Method, The Pharma. Innovation-J. Vol 2, no. 2, (2013), pp. 31-35.

11. U Kamalesh, $K$ Lalit, PA Stutie, $C$ Viney, Formulation and Evaluation of Mouth Dissolving Films of Paracetamol, Int. J. Pharm. Pharma. Sci. vol 6, no. 5, (2014), pp.199-202. 